\title{
Hearing the child's voice: a philosophical account
}

\author{
David Archard
}

Abstract: Article 12 of the UNCRC gives the child the right to have their views on self-regarding matters taken seriously and weighted according to the child's maturity. But it is not clear what such a right amounts to. This piece considers what it means to have a right to express views on such matters and what it means to have those views weighted, contrasting the child's right with an adult's right simply to make their own choices. It invites others to answer questions that arise from this philosophical exploration of the right to a 'voice'.

Keywords: Article 12, voice, self-regarding, best interest, maturity, weight.

Note on the author: David Archard is Emeritus Professor of Philosophy and Applied Ethics, at Queen's University Belfast. d.archard@qub.ac.uk 
This provocation paper follows an earlier paper I authored for the British Academy, which offered a philosophical analysis and evaluation of how we think about children and childhood, especially what it is that distinguishes childhood from adulthood, and what rights, if any, children have (Archard 2020).

The present paper focuses on the questions of why we should give a voice to children and of what kind of right might be granted to children if we do. ${ }^{1}$ The earlier paper identified the contrast between 'becoming' and 'being' as an influential way of understanding the difference between childhood and adulthood. The present piece can be read in this context by contrasting a child's right to express views and an adult's right to choose how to live.

\section{The appeal of Article 12}

Article 12 of the United Nations Convention on the Rights of the Child (UNCRC) formulates probably one of that charter's most central and influential rights. It gives every child 'who is capable of forming their own views the right to express those views freely in all matters affecting the child, the views of the child being given due weight in accordance with the age and maturity of the child'. This statement has an obvious intuitive appeal. Children should be listened to and the child's voice should be taken seriously. A great deal of published work in childhood and related studies not only defends the right of the child to be heard but creatively explores the various practical measures that might give effect to the right. ${ }^{2}$ Such work is immensely valuable. It puts the child and the child's voice at the heart of contemporary law and policymaking.

Yet the appeal of Article 12 is deceptively simple. The simplicity is deceptive because unpacking the Article discloses a host of difficulties of interpretation. What follows is a philosophical analysis and evaluation of what the Article attempts to capture as a fundamental right of the child.

\section{What does Article 12 claim?}

Let me first run through several important initial difficulties of interpretation before saying something about the central problems with this Article. In the first place, 'the

${ }^{1}$ The arguments in this piece owe much to ongoing discussions with my colleague, Suzanne Uniacke, Professor in Philosophy at Charles Sturt University.

${ }^{2}$ See, for instance, Daly (2018); Lundy et al. (2019) is a good guide to how the Article might be understood. 
child' is ambiguous between the collective noun and the designation of particular individuals. Should we listen to children as a group or to this child? A children's parliament might be an example of the former; child protection procedures to elicit the views of a specific child are an instance of the latter. Both senses of 'the child' can be intended, but I concentrate on the second interpretation in what follows. This is for the following reasons. It is very hard to understand how the maturity of a group of children can be assessed for the purposes of weighting any collective view. Not least, children as a group comprise many different ages and levels of maturity. Finally, a group of children can exercise the opportunity to have a say on matters affecting them, just as adults can. But it is only in the case of the individual child that the contrast with an individual adult is most obvious as I shall show in due course.

What for those who defend the child's right to be heard is the practical difference between hearing the collective voice of children and the individual voice of a single child?

Second, it is not every child whose voice we should hear, only those who are capable of forming views. Some have argued that even a new-born infant can express a view (Alderson 1993). Non-linguistic behaviours such as crying may serve to indicate feelings. But if such behaviours counted as the expression of views, we should attribute opinions to cats and dogs. Moreover, we need carefully to distinguish the questions of when a child can express a view and when a child can express a view that adults will properly understand both as the child's view and in the very terms that are intended by the child.

Nor should we take feelings as the expression of views.

Philosophers will insist that emotions differ from mere feelings in having what feelings lack, namely propositional content and being 'about' something (Scarantino $\&$ de Sousa 2018). Norway has incorporated the UNCRC into its domestic legislation and it takes 8 years as the age at which a child can form a view. This choice of age was evidence based, but it is for others to challenge it or offer an alternative account of when a child's views should be listened to.

Do those who work with or write on children disagree with something like this Norwegian fixing of the age at which the child can form and express a view?

Third, a right to express a view freely entails duties on the part of others. At a minimum the duty is not to stop a child from expressing a view. However, clearly it should mean more. The second clause of Article 12 stipulates that the child should be provided with the opportunity to be heard in relevant 'proceedings'. Yet still more is needed. Children can only express views if they are taught, facilitated, and supported in their expression. It is no good giving anyone a right to speak freely if they do not know how to and if they lack the means to do so. This raises important questions as to how children are taught to express their own views and about where - the protected spaces, the institutional frameworks, and social settings - they get to express their views. 
Fourth, the Article immediately following 12 protects the child's right to freedom of expression on any matter. So, what Article 12 specifically protects is two things: a right to express views on 'matters affecting the child' and a right to have those views given 'due weight'. Here is where it gets interesting and let me take each aspect of the right in turn.

\section{Self-regarding choices}

'Matters affecting the child' should be taken to mean what philosophers would term 'self-regarding' (Ten 1968), those that affect only the child and that make a significant difference to a child's well-being. Of course, everything makes a difference, even minor, to more individuals than the one to whom it makes the main difference. However, what is understood by self-regarding are those matters that are in the first instance about how the life of this particular self goes and that do not significantly affect others. For a child, this includes what is eaten, what is read, what is watched on television, what school is gone to, what work is done, who one's friends are, what medical treatments are proposed, and which parents are lived with after a separation or divorce.

To clarify and to separate issues: there are matters which affect us as adults and over which as citizens we claim a right to have a say-for instance, whether Heathrow has a third runway; how sex is taught in schools. Children might also be given a say on these matters in the sense of expressing a view. As a voter I can express my preferences on various matters, but I do so as one citizen amongst many and my individual vote will not automatically carry the day.

Children are not full citizens who have a right to vote. So they don't at present have, as adults do, a say. Should there be an age of suffrage, and, if there is, how else might we allow children as a group a say in those matters that adults get to decide as citizens?

Then there are some matters on which adults are thought by liberals to have not just a say but the right to make their own choices. Here we can see a real difference between adults and children. Self-regarding matters are those that, as John Stuart Mill argued in On Liberty, an individual adult should have unconstrained freedom of choice in respect of. According to his 'doctrine' we should be free to choose whether to eat harmful foods, refuse a medical procedure, run the risk of injury in enjoying dangerous sports, or to pursue a life of solitary asceticism. Mill famously qualified his statement of the doctrine by adding that 'it is hardly necessary to say' that it 'applies only to human beings in the maturity of their faculties'. He was, he made clear, not 'speaking of children' (Mill 1859: Chapter 1). 
On this familiar liberal account adults get to choose how to lead their own lives, whereas children only get to say how they would like to lead theirs. This contrast is an odd one and for this reason. When adults choose what they want to do or happen, it is not the case that they express a view and then that view is considered in deciding whether to allow them to do what they want. They simply choose and do so freely. In fact, they might not even express a view. They might say they are going to do what they have chosen to do. But if we do allow adults to make their own choices it is not because they say that this is what they want to do. It is simply that they have made the choice and for most of us most of the time we simply choose and then act.

Indeed, on Mill's account we should allow individuals to make their own choices even if the reasons they give for making those choices are palpably bad ones. An adult's view as to why they want to do something might reveal their choice to be imprudent, risky, unwise, self-harmful even. But so long as an adult is sane, knows what they are choosing, and chooses voluntarily, we should allow them to go ahead. Yet the views of children are assessed and weighted according to their maturity.

\section{Why listen to the child?}

Is this fair? Listening to the child should be for intrinsic and not instrumental reasons. The latter have to do with what a child's views tells us about what it might be best to do for the child. Remember that we are required to promote the child's best interest. This is a key principle of child welfare and child protection legislation and policy. Article 3 of the UNCRC states it as the 'primary consideration' in 'all actions concerning children'. Thus, we might interpret the imperative to hear the child as a good way to learn what is best for the child. For instance, by listening to the child we can gain a better sense of what is going on in the child's world and improve our overall judgment of what is best for them. Or, we can gauge from listening to the child what might be the costs of compelling the child to do what we think best if this clashes with what they want.

By contrast, to value the child's views for intrinsic reasons is to see the child as someone who has a view about what makes a difference to their life. We ought to respect someone capable of forming a view even if we disagree with the view and even if it does not, ultimately, make a difference to what we do. Just think of what is conveyed by stressing the personal pronoun in the question, 'But what do you think about all of this?' We respect an adult's choices even if we think them misguided because it is his or her choice. We should respect the child's views however wrong-headed they might be because they are theirs. 
Nevertheless, we need both to respect the child's views and do what is needed to ensure the best environment in which children can develop so that their views reflect what really matters to them.

We can thus ask those who work in child protection and child welfare, why exactly do they listen to the child, and is it for instrumental or intrinsic reasons? How do they balance listening to children with an assessment of their views as naïve, unwise, or unsafe?

Note that listening to the child as someone who has a view on self-regarding matters is not always the same as checking with an adult, 'Is that alright with you?' We might, for instance, do this where what we are not asking the other about something it is for them to decide. As a good neighbour we ask if next-door is OK with us painting our stucco rendering bright pink. It is our house and our choice. But we ought to find out what the neighbour thinks, and if he is not OK with our proposal this makes a difference. We have a reason to reconsider our choice of paint colour, not because he gets a choice over the matter but because his view is relevant. We might just worry about now having neighbours ill-disposed to us. But we might think that his approval matters because he is affected by what we are going to do, even if it is strictly none of his business.

In the case of the child, their views are on matters that would - if it were an adult in question - be for the person to choose. It would be their business. So, the child's views should be listened to and give us reasons to think again about what we might do if we were otherwise only concerned with doing what is best for the child.

Consider the case of medical decision-making. An adult has the power to consent or not to a proposed procedure - an operation, for instance- because in the famous words of the landmark US law case Schloendorff, 'Every human being of adult years and sound mind has a right to determine what shall be done with his own body. ${ }^{3}$ But the child has no such right. Yet when the child expresses the view that they would prefer not to have the operation, that matters. It does so not simply because it tells us about the child's fears or likelihood of resisting the doctors. It matters because it is the child's view about their body.

Is this how and why paediatric medical personnel should involve children in decision-making?

${ }^{3}$ Schloendorff v. Society of New York Hospital, 211 N.Y. 125, 105 N.E. 92, 93 (1914). 


\section{Weighting the child's views}

Article 12 does not just ask us to listen to the child. It adds that we should give 'due weight' to the child's views 'in accordance with their age and maturity'. What does that mean exactly?

In the first place, this requirement of giving due weight to a child's views reflects something important. It is not enough to let a child express a view, nor even to listen. We could listen attentively, conscientiously, carefully, and diligently. That would be insufficient. For even in the case of adults we know that we can be heard but nevertheless ignored inasmuch as what we say has no effect. So, a child's expression of a view must make some difference. The question is how much difference and why.

Presumably, we must give the child's views more weight the more mature she is. It is the maturity of the child and not of her views that counts. An immature person can give expression to mature views, and vice versa. And it is maturity that is in question; age as such is irrelevant and, anyway, correlates imperfectly with degrees of maturity.

Moreover, the 'maturity of faculties' to which Mill refers is not simply for him a matter of greater cognitive ability. For what is important is not just being able to know more, it is crucially about a greater understanding and appreciation of relevant matters. Thus, for example, Lord Scarman required of a mature minor-one who could be accorded the right to choose- - sufficient understanding and intelligence to understand fully what is proposed'. ${ }^{4}$

Imagine then that a 13-year-old wants something - not to have an operation, not to go to school or not to study some particular subject, to take on a paid job, to live with her mother and not her father after their separation - how do we give due weight to her views?

First, we assess her maturity, taking care not simply to read that off from our evaluation of her views or from her age. Then we give her views the weight that is due or appropriate given that level of maturity.

But what exactly does that mean in practical terms? The weightier the views the more chance they have of leading us to do what the child has expressed a preference for; the more consideration we give to the views; the more time we allow the child to explain and defend her views; the further we go to meeting what she wants; or what? If we judge a child mature enough to have her views be decisive, then we treat her, for all practical purposes, as if she was an adult. Yet, if she is not that mature, the difference her views might make to the outcome is simply obscure.

This is the crucial difference between a threshold account of maturity and a scalar or gradated one. On the first—most obviously in the celebrated Gillick judgment—a

${ }^{4}$ Gillick v West Norfolk \& Wisbeck Area Health Authority [1986] AC 112 House of Lords, 187. 
child might display enough maturity to have her views be decisive. On the latter-as in Article 12-a child can display degrees of maturity and have her views be proportionately weighted. The first provides a clear and determinate means of allowing the child to choose as if an adult; the second provides an unclear and imprecise means of giving the child more or less say in what happens.

How, we could ask psychologists, sociologists, and educationalists, should we assess a child's understanding and intelligence - for the purposes of estimating the right weight to give their views or to determine whether the child is mature enough to make their own choices? How would they understand the relevant 'maturity of faculties'? How is any such assessment free from the biases of class, culture, and gender? Can we have a genuinely neutral and independent metric of 'maturity'?

We can also ask those who work in the law or jurisprudence whether we should think of a child's maturity as either enough (or not) to be considered an adult with a right to choose, or as a matter of degrees with corresponding levels of influence over what is done in their name. And what would this latter look like in legal terms?

\section{The importance of making sense of Article 12}

The foregoing may strike some as mere philosophical nit-picking and an avoidance of the need to address urgent practical matters. But good practice only follows from clarity of purpose. Of course, it is important that a child's voice is heard, and that this means more than simply allowing the child to express her views. Otherwise, one is only granting children freedom of expression and not-as Article 12 clearly is intended to allow for-the opportunity to have a meaningful say in what happens to them. This much is agreed by all who work on the topic of childhood and who seek to make law and policy that properly involve children in decision-making about their own lives. Yet such work - for all its tremendous value - should also recognise that Article 12 is a hugely complex statement of the idea of listening to the child's voice. Making good sense of what it means to listen to the child and of how Article 12 is or is not a useful formulation of that imperative, is actually a very difficult task. It is one philosophical analysis and evaluation can help with.

Acknowledgements: The arguments in this piece owe much to ongoing discussions

with my colleague, Suzanne Uniacke, Professor in Philosophy at Charles Sturt University. 


\section{References}

Alderson, P. (1993), Children's Consent to Surgery (Milton Keynes, Open University Press).

Archard, D. (2020), 'How Should We Think About Childhood and Children? A Provocation Paper', Medium.

https://medium.com/reframing-childhood-past-and-present/how-should-we-think-about-childhoodand-children-66c5624092f

Daly, A. (ed.) (2018), 'Special Issue: According Due Weight to Children's Views', International Journal of Children's Rights, 26(1).

Lundy, L., Tobin, J. \& Parkes, A. (2019), 'Article 12: The Right to Respect for the Views of the Child', in J. Tobin (ed.), The UN Convention on the Rights of the Child: A Commentary (Oxford, Oxford University Press).

Mill, J. S., (1859), On Liberty (London, John W. Parker and Son).

Scarantino, A. \& de Sousa, R. (2018), 'Emotion', in Stanford Encyclopedia of Philosophy. https://plato.stanford.edu/entries/emotion/\#EarlFeelTradEmotFeel

Ten, C. L. (1968), 'Mill on Self-regarding Actions', Philosophy, 43(163): 29-37. https://doi.org/10.1017/S0031819100008834

To cite the article: Dave Archard (2020), 'Hearing the child's voice: a philosophical account', Journal of the British Academy, 8(s4): 7-15. DOI https://doi.org/10.5871/jba/008s4.007

Journal of the British Academy (ISSN 2052-7217) is published by The British Academy, 10-11 Carlton House Terrace, London, SW1Y 5AH www.thebritishacademy.ac.uk 
